\title{
Responsive Parenting: Establishing Early Foundations for Social, Communication, and Independent Problem-Solving Skills
}

\author{
Susan H. Landry \\ University of Texas Health Science Center at Houston
}

\author{
Karen E. Smith \\ University of Texas Medical Branch
}

\author{
Paul R. Swank \\ University of Texas Health Science Center at Houston
}

\begin{abstract}
Mothers whose infants varied in early biological characteristics (born at term, $n=120$; born at very low birth weight [VLBW], $n=144)$ were randomized to a target group $(n=133)$ or developmental feedback comparison group $(n=131)$ to determine whether learning responsive behaviors would facilitate infant development. The target condition included videotaped examples, problem-solving activities, and mothers' critique of their own behaviors through video procedures across 10 home visits. All target versus comparison mothers showed greater increases across multiple responsiveness behaviors observed in 4 assessments conducted across 6-13 months of age; changes in emotionally supportive behaviors were strongest for target mothers of infants born at VLBW. Increased maternal responsiveness facilitated greater growth in target infants' social, emotional, communication, and cognitive competence, supporting a causal role for responsiveness on infant development. Although benefits were generally comparable across risk groups, aspects of social and emotional skills showed greater change for those born at VLBW. Evidence for responsiveness as a multidimensional construct was provided as well as the importance of different aspects of responsiveness mediating the effect of the intervention on different infant skill domains.
\end{abstract}

Keywords: very low birth weight, responsive parenting, parent intervention, language input, infancy

Decades of interest in responsive parenting is based, in part, on the critically important role it is thought to play in promoting children's social-emotional, cognitive, and language outcomes (e.g., Bornstein \& Tamis-LeMonda, 1989; Londerville \& Main, 1981; Olson, Bates, \& Bayles, 1984). Responsiveness is an aspect of supportive parenting referred to in several theories and research frameworks including attachment (Ainsworth, Blehar, Waters, \& Wall, 1978; Sroufe, 1983), sociocultural (Rogoff, 1990; Vygotsky, 1978), and socialization of young children (Grusec \& Goodnow, 1994; Maccoby \& Martin, 1983). Although responsiveness has a central role in various research frameworks, to date, much of researchers' knowledge regarding the influence of responsive parenting on children's development is based on descriptive studies (e.g., Bornstein \& Tamis-LeMonda, 1989; Landry, Smith, Swank, Assel, \& Vellet, 2001). Although observational research can pro-

Susan H. Landry and Paul R. Swank, Department of Pediatrics, Children's Learning Institute, University of Texas Health Science Center at Houston; Karen E. Smith, Department of Neurology, University of Texas Medical Branch.

This study was supported by National Institutes of Health Grant HD36099.

Additional materials are on the Web at http://dx.doi.org/10.1037/00121649.42.4.627.supp.

Correspondence concerning this article should be addressed to Susan H. Landry, Department of Pediatrics, Division of Developmental Pediatrics, University of Texas Health Science Center, 7000 Fannin, Suite 2300, Houston, TX 77030. E-mail: susan.landry@uth.tmc.edu vide strong empirical support for inferring the importance of responsive parenting for children's development, experimental designs are necessary to further researchers' understanding of a causal influence.

A recent meta-analysis on the available interventions targeting the influence of maternal sensitivity-responsiveness demonstrates support across a relatively small number of studies for the importance of this parenting style on an aspect of social-emotional development, attachment security (Bakermans-Kranenburg, van IJzendoorn, \& Juffer, 2003). A second small group of intervention studies targeting responsiveness has specifically focused on highrisk children (e.g., premature, high irritability, adopted), with evidence of positive consequences for cognitive and social skills (e.g., Beckwith \& Rodning, 1992; Juffer, Hoksbergen, RiksenWalraven, \& Kohnstamm, 1997). In the present experimental study, we addressed a number of objectives to further understand the influence of responsive parenting on a broad range of infant behavior.

\section{Objective 1 and Related Hypotheses: Determine Whether Changes in a Range of Maternal Responsiveness Behaviors Result in Increases in Infant Skills}

Examination of the responsiveness behaviors described in studies from different theoretical orientations reveals at least four aspects: contingent responding, emotional-affective support, support for infant foci of attention, and language input that supports developmental needs. Warm acceptance of infants' needs and 
interests with responses that are prompt and contingent on infants' signals are often considered as behaviors that are responsive (e.g., Ainsworth et al., 1978; Sroufe, 1983). These are thought to support infants' ability to self-regulate by facilitating the development of mechanisms for coping with stress and novelty and, ultimately, a trust and bond with the caregiver through the process of internalization (Ainsworth et al., 1978; Bornstein \& Tamis-LeMonda, 1989). This, in turn, promotes an interest and willingness for infants to explore their environment, to continue to signal, and to cooperate with caregiver requests (Baumrind, 1989; Darling \& Steinberg, 1993). The process is thought to occur through a threeterm chain of events in which infants signal, mothers respond in a prompt and sensitive manner, and infants experience that their needs are met in a predictable way (e.g., Bornstein \& TamisLeMonda, 1989).

Behaviors that emphasize emotional support may include the presence of positive affective input (e.g., warmth, smiling) and the absence of highly negative behaviors (e.g., harsh voice tone, physical intrusiveness) and are thought to communicate affectively the caregiver's interest and acceptance (e.g., Darling \& Steinberg, 1993). Contingent responsiveness and emotional support are described as having a particular importance for children's social development (e.g., cooperation, regulation of affect) because they alter children's openness to parental socialization practices and facilitate an understanding of how to make appropriate choices (Grusec \& Goodnow, 1994; Maccoby \& Martin, 1983).

Support for infant foci of attention, a behavior associated with a sociocultural framework, is thought to facilitate higher levels of learning and self-regulation because it provides a structure, or scaffold, for infants' immature skills (e.g., Bruner, 1972; Rogoff, 1990; Vygotsky, 1978). Responsive parenting within this framework includes behaviors that encourage joint engagement and reciprocity in dyadic interactions (e.g., Bakeman \& Adamson, 1984; Trevarthen, 1988). Maintaining as opposed to redirecting supports infants' immature attention and cognitive capacities by not requiring a shift in attentional focus (Tomasello \& Farrar, 1986). This type of sensitive parental input guides and structures interactions so that the child begins to take a more active role and, ultimately, assumes regulation of his or her own behavior (Rogoff, 1990; Vygotsky, 1978). Maintaining frequently relates to greater vocabulary development (e.g., Akhtar, Dunham, \& Dunham, 1991) and greater object exploration (Landry, Garner, Swank, \& Baldwin, 1996).

Conversations with infants have specific characteristics that appear to support early language development. In a study investigating the genetic versus environmental influences on infant communicative competence, two important early direct environmental influences that were not confounded by shared genetic variance were mothers' imitation of their infants' vocalizations and mothers' contingent vocal responsivity (Hardy-Brown \& Plomin, 1985). Research also emphasizes how important it is for children to receive rich language input (e.g., providing labels of objects and actions and how these go together or function) in order to develop vocabulary and semantic knowledge (Hart \& Risley, 1995; Weizman \& Snow, 2001) and acknowledges the importance of this occurring in infancy (Bruner, 1972; Kuhl et al., 1997).

As there is limited experimental research addressing whether multiple aspects of responsiveness support infant development, our first objective was to determine whether increases in mothers' responsive behaviors resulted in increases in four aspects of infants' skills across the 1st year of life. To evaluate this possibility, we conducted a randomized, experimental study in which we first determined whether mothers could be facilitated to increase their use of contingent responsiveness, emotional-affective support, support for infant foci of attention, and quality of language input. Target in contrast to the comparison mothers were hypothesized to show higher levels and greater increases for each of these behaviors (Hypothesis 1a). When interacting with their mothers, the target infants in contrast to those in the comparison group also were expected to show higher levels and greater increases in three skill areas: social (i.e., cooperation with maternal requests), early communication (i.e., word use), and affective (i.e., increases in positive and decreases in negative) domains (Hypothesis 1b).

To determine the extent to which these skills generalized to situations in which mothers were not present, we evaluated these same skills while infants were interacting with a novel adult as well as in independent toy play. We hypothesized that when interacting with a novel adult, target in contrast to comparison infants would demonstrate higher levels and greater growth in the same three skill areas evaluated when interacting with their mothers (Hypothesis 1c). This situation was expected to be more stressful because the adult was unfamiliar and, although responsive, did not attempt to scaffold the infant's individual learning needs. This finding would support the notion that increased maternal responsiveness helps infants develop resources for coping with stress and novelty (Goldberg, Grusec, \& Jenkins, 1999) and learn to self-regulate when maternal support is not present (Rogoff, 1990). In the second situation, an independent goal-directed play task examining aspects of infants' cognitive skills, the target in contrast to the comparison infants were expected to show greater gains in their play skills, as functional play with objects is theorized to first occur in a social context with caregivers (Hypothesis 1d; Bruner, 1972).

Objective 2 and Related Hypothesis: Determine Whether There Is Differential Effectiveness of Responsiveness for Varying Infant Characteristics

To date, there is limited experimental research on the differential impact of responsiveness for infants who vary in birth status, as most intervention studies of infants born preterm do not include infants born at term (e.g., Patteson \& Barnard, 1990). If the process by which responsiveness facilitates children's development is through parental sensitivity and willingness to meet infants' individual needs, then one could hypothesize that responsive parenting would have positive consequences that are comparable for children of varying characteristics (Hypothesis 2). To test this possibility, we included children born preterm at very low birth weight (VLBW) to determine whether they would show comparable increases in four skill areas. Similar effects of responsiveness on high-risk children's development would be consistent with descriptions of the potential powerful self-righting tendency of the caregiving environment to compensate for the types of biological disadvantages experienced, for example, by infants born at VLBW (Sameroff, Seifer, \& Zax, 1982). Caregiving is frequently described as an important factor for preventing less optimal developmental pathways for children who vary in their vulnerability for 
negative outcomes, and support for this finding is found in observational studies (Landry et al., 2001).

\section{Objective 3 and Related Hypotheses: Evaluate Whether Different Aspects of Responsiveness Mediate the Intervention Impact on Domains of Infant Development}

Studies emphasizing responsiveness in terms of the contingency of the response in ways that provide affective-emotional support report outcomes such as secure attachment (BakermansKranenburg et al., 2003), use of social strategies (Goldberg, Lojkasek, Gartner, \& Corter, 1989), and decreased problem behaviors (Wakschlag \& Hans, 1999). However, it has been suggested that responsiveness is a broader construct that includes distinct but conceptually related behaviors that provide support for a range of cognitive and social skills (Martin, 1989; Van Egeren, Barratt, \& Roach, 2001). Studies defining responsiveness as a broader construct comprising behaviors such as supportive stimulation (e.g., language input), in addition to contingent responsiveness to signals, report positive consequences for cognitive skills (e.g., Bornstein \& Tamis-LeMonda, 1989) and greater growth in both social and cognitive-language skills (Landry et al., 2001). Rarely have different aspects of responsiveness (e.g., contingency, stimulation) been considered within a single investigation, and thus there is limited information on the extent to which different aspects relate to different child outcomes. It may be that behaviors typically examined in relation to secure attachment and/or social skills also are important for children's concept development and language skills because they provide support for children's efforts through positive affect and warmth. An observational study that did examine responsiveness from an interface of these two frameworks found that emotional support and verbal input played a role in understanding language development (Tamis-LeMonda, Bornstein, \& Baumwell, 2001).

Thus, the third objective was to determine whether different aspects of responsiveness mediated the impact of the intervention on different domains of infant skills and whether this was moderated by VLBW status. We hypothesized that responsive behaviors from an attachment framework would be particularly important for infant social skills, whereas those from a sociocultural framework would be important for understanding increases in early language and cognitive development (Hypothesis 3a). In light of our expectation that responsive behaviors would have a similar effect across infants born at VLBW or at term, birth status was not expected to moderate these relations (Hypothesis 3b).

The literature describes multiple aspects of responsiveness that may provide differential support of infant development (e.g., social, cognitive). To date, however, there are limited empirical studies that provide a test of the causal influence of these behaviors on multiple aspects of infant development and whether this impact differs for infants of varying characteristics. Thus, this study addresses these goals.

\section{Method}

\section{Participants}

A medical record review approved by the Institutional Review Board was used to determine eligibility and contact information. The cohort was recruited from three hospitals serving families from lower income backgrounds and included 264 mother-infant pairs who participated in 10 weekly home visits when the infant was 6-10 months of age

In order to obtain a randomly split sample between the two study conditions while also keeping the infant risk groups equal across conditions, we used an equal number of markers per condition for each risk group and drew out one marker per family, without replacement, after the preassessment was completed. Of families contacted, $35 \%$ declined, but no differences were found for a range of medical and demographic factors (e.g., gender, birth weight) for participants versus decliners. Study attrition, defined as not completing all 10 home visits and the pre-, interim, post-, and follow-up assessments, was $9 \%(n=24)$ and primarily was due to families' inability to complete the program because of scheduling problems or moving outside the study area. On a range of variables shown in Table 1 , the only difference between families completing the program versus those lost to attrition was for ethnicity, $\chi^{2}(3, N=282)=13.49, p<.004$ African American and "other" ethnicities were represented at higher numbers in the attrition group compared with Hispanic and Caucasian ethnicities, $\chi^{2}(1, N=282)=12.22, p=.0005$.

Expected differences were apparent between the infant risk groups on medical variables for birth weight, $F(2,248)=1,430, p<.0001$, and

Table 1

Comparison of Infant, Maternal, and Program Characteristics by Intervention Condition

\begin{tabular}{lcc}
\hline \multicolumn{1}{c}{ Variable } & PALS $(n=133)$ & DAS $(n=131)$ \\
\hline Infant & & \\
$\quad$ Birth weight (in mean grams; high-low-term) & $833-1,256-3,385$ & $918-1,412-3,332$ \\
Gestational age (in mean weeks; high-low-term) & $27-30-40$ & $27-31-40$ \\
Risk status (\%; high-low-term) & $28-38-34$ & $25-37-38$ \\
Gender (\%; male-female) ${ }^{\mathrm{a}}$ & $45-55$ & $52-48$ \\
Maternal & & \\
Age (in years; $M-S D)$ & $27.8-5.7$ & $27.0-6.2$ \\
Education (in years; $M-S D)$ & $12.6-2.6$ & $12.6-2.4$ \\
Socioeconomic status $(M-S D)^{\mathrm{b}}$ & $31.0-12.3$ & $32.7-12.3$ \\
One parent-two parents $(\%)$ & $62-38$ & $55-45$ \\
Ethnicity (\%; African American-Caucasian-Hispanic-Other) & $37-34-27-2$ & $29-36-31-4$ \\
Time to complete program (in weeks; $M-S D)^{\mathrm{a}}$ & $14.5-3.5$ & $13.4-3.2$ \\
\hline
\end{tabular}

Note. $\quad$ PALS $=$ playing and learning strategies; DAS $=$ developmental assessment screening.

${ }^{a}$ Significant difference in PALS versus DAS condition at $p<.05 .{ }^{\mathrm{b}}$ Based on Hollingshead's (1975) four-factor scale. 
gestational age, $F(2,254)=1,364, p<.0001$, but no differences between treatment conditions were found when collapsing across risk group (see Table 1). Use of early intervention services also varied significantly by risk group, $\chi^{2}(2, N=282)=43.99, p<.0001$ (high risk-VLBW: $M=37 \%$; low risk-VLBW: $M=12 \%$; term: $M=2 \%$ ), but did not differ by study condition. Table 1 shows a relative balance for the study conditions across three major ethnic groups, with families, on average, having two children, and shows that gender was the only demographic that differed across conditions, $\chi^{2}(1, N=282)=5.01, p<.03$. Socioeconomic status (Hollingshead, 1975) was in the upper-lower-class to lower-middle-class range $(M=31.8, S D=12.3)$, which is consistent with a high school education and clerical or semiskilled occupations. Target in contrast to comparison mothers took 1 week longer to complete the program, $F(1$, $151)=4.09, p<.05$, as extra time was required to schedule two home visits with an alternate caregiver.

\section{Procedure}

Both study conditions required families to meet with a facilitator in their homes for 10 visits that lasted about $1.5 \mathrm{hr}$, with the intent of visits occurring on a weekly basis. Families were seen by staff masked to study condition for assessments to evaluate maternal and infant behaviors, scheduled at ages corrected for gestational age. Each assessment included videotaped living room and toy play situations and occurred 2 weeks prior to Home Visit 1 ( $n=264$; infant age: $M=6.2$ months, $S D=0.66)$, after Home Visit 5 ( $n=253$; infant age: $M=8.4$ months, $S D=1.1), 2$ weeks after the final Home Visit $10(n=258$; infant age: $M=10.7$ months, $S D=$ 1.5 ), and about 3 months later ( $n=240$; infant age: $M=13.1$ months, $S D=1.5$ ). In order for participants to be assessed at the post- and follow-up evaluations, all 10 home visits had to be completed. Thus, each family was seen for 14 visits.

Rationale and description for the intervention condition. The playing and learning strategies (PALS) condition incorporated factors known to impact intervention efficacy: short term, starting later in 1st year of life, a clearly defined focus, and linking intervention goals to theoretical models (Bakermans-Kranenburg et al., 2003). It also acknowledged the importance of including the family's social context into the intervention, supporting facilitators to accept the role of change agent and involving mothers by active construction of knowledge and practice. The PALS home visits were guided by a detailed curriculum that included behaviors linked to the four aspects of responsiveness supported by the literature, and the format included facilitators (a) asking mothers to review their experiences across the last week related to their efforts to try the targeted behaviors, (b) describing the current visit's targeted behavior, (c) watching and discussing with mothers the educational videotape of mothers from similar backgrounds, (d) videotaping mothers interacting with their infants in situations that the mothers selected (e.g., toy play, feeding, bathing) with coaching, (e) supporting mothers to critique their behaviors and the infants' responses during the videotaped practice, and (f) planning with mothers as to how to integrate responsive behaviors into their everyday activities with laminated cards defining the behavior and its importance provided to support practice.

A key component of the intervention was the facilitator coaching mothers to use the target behaviors, including commenting on the infants' responses when these behaviors were used. This procedure provided mothers with immediate feedback about their success in using targeted behaviors and supported them to begin to pay close attention to the impact these behaviors had on their infants. Thus, mothers had immediate feedback in their success in using the behaviors and how to start paying close attention to their impact on their infants. Facilitators were trained to use the curriculum in a flexible manner to meet the learning needs of individual families. Table 1 in the Appendix (which is available on the Web at http:// dx.doi.org/10.1037/0012-1649.42.4.627.supp) provides a detailed description of the goal for each home visit.

Description of the comparison condition. For the comparison condition, developmental assessment screening (DAS) facilitators made the same number of home visits, scheduled similar to the PALS condition. Visits included discussion with mothers about new infant skills observed during the previous week, assessment of infant development across a range of skills with a screening measure, and feedback provided to mothers. Maternal questions about infant skill levels were answered, and mothers were provided handouts on common issues such as sleep, feeding, and pacifiers. PALS mothers also received these handouts. When mothers had questions regarding how to facilitate infant development, they were encouraged to talk with their health care providers.

Systematic training of facilitators and assessment of fidelity of intervention implementation. Initial training for both conditions occurred with a review of the procedures and role play as well as discussion of what type of information could and could not be provided in each condition. Implementation fidelity occurred through a stringent monitoring system to assure that fidelity remained at high levels throughout the study period using two approaches. First, study investigators accompanied each facilitator on monthly intervention and control home visits during which strengths and weaknesses were documented. These were then discussed and adjusted to ensure the study conditions were faithfully implemented. Also, monthly 3-hr group meetings were held in which facilitators worked with senior investigators and reviewed their videotapes of home visits and discussed problems. This step informed the development of an implementation manual that provided systematic information regarding challenges with suggested solutions.

Another aspect of fidelity, mothers' knowledge and skill, was documented with a checklist in Sessions 4 and 8 as the mother taught behaviors to an alternative caregiver. For each concept, mothers were rated across $0-4$ on the basis of the extent to which she could demonstrate and explain the importance of the concept. A score of 4 was found for $50 \%$ of mothers across the six concepts, and a score of 3 was found for $58 \%-87 \%$ of the mothers depending on the concept. Contingent responsiveness, a complex concept, showed understanding at this level for $81 \%$ of the mothers.

Assessment procedures. With the exception of 4 families evaluated in their homes, all infants and their mothers were evaluated in the developmental laboratories at the two sites (Houston, Texas, and Galveston, Texas). At each assessment, infant communication and social skills were evaluated with videotaped procedures while they interacted with their mothers and an examiner. Their independent goal-directed play also was evaluated using videotaped coding procedures. The social interaction with mothers involved a 15-min naturalistic living room situation in which mothers were requested to do what they would typically do with their infants. Books, toys, magazines, and other items found in a living room were provided during this time similar to longitudinal study procedures previously used (Landry et al., 2001). A second context, the toy play situation, was included to determine whether results were similar across types of activities. In toy play, mothers were provided a group of toys and asked to play for $10 \mathrm{~min}$ with one or more of the toys with their infant.

\section{Measures}

Maternal observed behaviors. Observational measures quantified with either frequencies or global ratings evaluated changes in targeted behaviors in the two contexts, as these are sensitive to variability in maternal interactive behaviors and the prediction to later developmental outcomes (Landry, Smith, Miller-Loncar, \& Swank, 1998). The use of frequencies and ratings together is thought to capture the most information about parenting behaviors (Darling \& Steinberg, 1993). Ratings are an effective means for assessing behaviors that reflect a disposition that permeates all of a mother's interactive behaviors (e.g., contingent responsiveness; Bakeman \& Brown, 1980), whereas frequency counts capture aspects of maternal behavior where quantity is important (e.g., maintaining)

Targeted behaviors were conceptualized into four types related to the scaffolding support provided. All targeted mother behaviors have been included in a large body of previous descriptive research and have shown to predict various aspects of infant and child development (e.g., exploratory 
goal-directed play, language, following requests; e.g., Landry et al., 1996; Landry, Smith, Swank, \& Miller-Loncar, 2000). Contingent responsiveness was coded as one type of maternal responsiveness. The second type, emotional-affective support, included both responsive (i.e., positive affect, warm sensitivity) and nonresponsive (i.e., restrictiveness, physical intrusiveness, harshness voice tone) behaviors. The third type, support of infant foci of attention or maintaining of infant attention, was coded as positive responsiveness, whereas redirecting was considered a lack of responsiveness. The final type, quality of language input, included verbal scaffolding, labeling of objects and actions, and verbal encouragement. Definitions for coding of the observed behaviors are provided in Table 2 of the Appendix, which is available on the Web at http://dx.doi.org/ 10.1037/0012-1649.42.4.627.supp.

Mothers' interactions were quantified using rules separating them into events based on verbal and nonverbal behavior and time separating these behaviors using procedures previously described (Landry et al., 2001). Global ratings using a 5-point scale were used to quantify other maternal behaviors. Two of the mother behaviors coded for multiple levels (i.e., labeling objects and actions) were combined into two variables using a scaling technique: labels for objects and labels for actions. One approach to scaling discretely ordered responses is to use an ordinal regression model with a random intercept term. A cumulative probability, or proportional odds, model was used with random intercept and fixed response scale effects to estimate a latent variable level using a nonlinear mixed modeling process (SAS Institute, 1999). As the latent variable increases, the likelihood that the mother engages in higher levels of labeling increases.

Infant behaviors with mothers. Behaviors were coded as responses if they followed within $3 \mathrm{~s}$ of a maternal attention-directing event. Outside of this interval, we also coded for infant behaviors that attempted to attract their mothers' attention. For the social domain, infant cooperation with requests was coded. Word approximations and use of words were coded for the communication domain, and negative and positive affect were coded for the emotional domain. Definitions for all infant behaviors are included in Table 3 of the Appendix, which is available on the Web at http://dx.doi.org/10.1037/0012-1649.42.4.627.supp.

Infant behaviors with examiner. Infants also were evaluated in a toycentered, scripted interaction with an examiner while seated in an infant chair with an attached adjustable table tray. Although the requests were scripted to assure a standard procedure, examiners were trained to engage infants with positive voice tone, facial expression, and pacing as well as to hold the infant's attention with positive verbal encouragement. The script included 20 interactive events in which infants were requested to engage verbally or gesturally with the examiner who sat facing the infant so that joint attention and eye contact easily could be accomplished. For example, the examiner would say, "Hi, [baby's name]. Can you talk to me? What can you tell me?" or "Here is Lenny the lion [puppet]. He has funny hair. Do you want to touch it?" After each request, the examiner paused for 10 -s to allow the infant ample time to engage with the object, vocalize, or use other social behaviors. In order to make the 10 -s pause appear natural, the examiner continually engaged all infants with head nods or short verbal encouragements such as "yeah" or "okay."

Independent goal-directed play. Infants were videotaped while playing alone with five sequentially presented toys (rainstick rattle, nesting cups, five blocks and a cup, flutter rattle, smiley face manipulative toy). Each toy was presented for $1 \mathrm{~min}$ while the examiner, who remained in the room, only interacted minimally to bids for attention by saying she could not play. When an infant was off task for a 15 -s period (i.e., not touching or looking at the toy), examiners nonverbally prompted the infant to return to play by tapping on the tray or a by giving a brief demonstration. A description of the coding scheme for this measure and its use with similar populations is found in other publications (Landry, Miller-Loncar, Smith, \& Swank, 2002; Landry et al., 2000). Every $10 \mathrm{~s}$, the highest level of infant play was determined on the basis of a hierarchical level-of-play scale that ranged from 1 (off task) to 13 (goal-directed play with mastery) based on developmental sequences reported in the literature (e.g., Fenson, Kagan, Keasley, \& Zelazo, 1976), although for these infants, behaviors most often included looking with or without holding to active manipulation and early functional use of toys. The percentage of the 10-s intervals across toys that included functional play was used in data analyses.

In previous studies, this measure has been correlated with the Bayley Mental Scale (Bayley, 1993), providing concurrent validity for the task's ability to capture early cognitive abilities. Additional support comes from descriptive studies in which independent play at 4 and 6 years was predicted by early cognitive language (Landry et al., 2000) and nonverbal reasoning ability (Landry et al., 2002).

Coding procedures and interrater reliability. The coding staff from both sites (Houston: $n=4$; Galveston: $n=2$ ) was trained by an expert, senior coder under the direction of Susan H. Landry. Initial training involved each member achieving interrater agreements greater than or equal to $80 \%$ per variable. To guard against observer drift, we conducted monthly cross-site meetings in which videotapes were coded as a team and interrater agreements were checked to assure that they continued to meet the criterion of greater than or equal to $80 \%$ per variable. In coding mother and infant behaviors in the living room context, we randomly chose one of the three 5 -min segments for coding. For the toy play context, the first 5 min of interaction was coded.

For all observed behaviors, a second rater coded $15 \%$ of the videotapes, and generalizability coefficients using repeated measures analyses of variance were calculated (Fleiss, 1986). This method is recommended for studies using continuous, behavioral observational data and has the advantage of evaluating both the consistency across participants for each rater (absolute) and the rater variance within participants (relative) for those variables used in the analyses (Frick \& Semmel, 1978). Coefficients above .50 indicate adequate reliability (Mitchell, 1979). Generalizability coefficients for the maternal behaviors were as follows: contingent responsiveness, $r=.74$; attention maintaining, $r=.81$; attention redirecting, $r=.77$; verbal scaffolding, $r=.64$; verbal encouragement, $r=.78$; positive affect, $r=.74$; warm sensitivity, $r=.74$; physical intrusiveness, $r=.45$; restrictiveness, $r=.75$; harshness of voice tone, $r=.70$; label one object, $r=.77$; label greater than one object, $r=.77$; label one action, $r=.70$; label greater than one action, $r=.75$. Generalizability coefficients all were within adequate ranges (.50), with the exception of physical intrusiveness, which may have been less reliable because of its low incidence.

Generalizability coefficients for infant behaviors when interacting with their mothers and examiner were as follows for mothers and examiners, respectively: words, $r \mathrm{~s}=.68$ and .76 ; cooperation, $r \mathrm{~s}=.62$ and .75 ; positive affect, $r \mathrm{~s}=.85$ and .84 ; negative affect, $r \mathrm{~s}=.84$ and .76 . The generalizability coefficient for infant independent play behavior was $r=$ .75. In general, reliabilities for the infant behaviors were higher when interacting with the examiner versus mothers. This was most likely due to the degree of structure provided by the scripted nature of this task.

\section{Results}

\section{Objectives 1 and 2: Determine Whether Changes in a Range of Maternal Responsiveness Behaviors Result in Increases in Infant Skills and Whether This Is Differential for Infants of Varying Characteristics}

Choice of data analysis approach. Growth curve modeling (GCM) procedures were chosen to address Objectives 1 and 2 because these yield individual growth curves for each mother and infant with multiple growth parameters (i.e., intercept, slope, curvature). This allows for evaluation of differences between study conditions at the end of the intervention (i.e., level) and in the rate of change across the intervention period. Unlike traditional re- 
peated measures approaches, GCM allows the inclusion of data for all families that had at least two assessments, variability in age of assessment, and examination of predictors for individual patterns of growth. With GCM, parameters were allowed to be random when there was individual variation across participants for that parameter but fixed when there was minimal to no variation or when variation was limited to group differences (Bryk \& Raudenbush, 1992). Whether parameters were random or fixed in each model is included in the tables summarizing the data analyses.

GCM requires that an age point be selected to set as the intercept. Because our main objective was to evaluate the intervention effectiveness, the intercept was set at the 12-month age point in order to evaluate for differences between the two study conditions at the end of the intervention. Examining for differences in slope and curvature parameters between the two conditions also directly addressed Objectives 1 and 2. Significant differences on the slope parameter provide information regarding the rates of linear change between the intervention conditions, and differences in curvature parameters indicate that the groups differ in nonlinear change. For example, if the two study conditions (PALS vs. DAS) are comparable at preassessment, a significant 12-month intercept difference demonstrates a condition effect. In the presence of results supporting the effectiveness of the intervention, level and slope differences provide evidence that treatment effects were maintained during the no-treatment follow-up period.

Mother and infant behaviors at preassessment did not differ across intervention groups except for mothers' use of redirecting, $F(1,475)=4.59, p=.04$, where the effect size was small $(d=$ $0.11)$. Because the pretest data are included in growth modeling analyses, any differences in the study conditions prior to the intervention are taken into account in the change over time estimates. Although significant differences were found between the two study conditions on infant gender, when this was included in the models, results did not change and therefore model results without gender are reported.

Matching analyses to distribution of variables. All variables were analyzed using one of two mixed models: (a) linear mixed model analyses that required data with a normal distribution or (b) nonlinear mixed model analyses that were appropriate for positively skewed distributions. As several of our maternal variables showed a negatively skewed distribution, they were reversed scored in order to shift their distribution to one that was positively skewed. Thus, for these variables (i.e., contingent responsiveness, warmth, positive affect), lower parameter estimates indicate a more optimal change in the tables summarizing the data analyses. In addition, for ease of interpretation, these three variables are illustrated in the figures using the original 1-5-point scale, with high scores showing more positive behavior. The variables analyzed using a linear mixed model analyses included (a) maintaining, redirecting, labeling, physical intrusiveness, and voice tone for mother; (b) cooperation for infant with mother; and (c) use of words for infant with examiner; and (d) independent toy play for infant (SAS PROC MIXED; SAS Institute, 1999). The following variables were analyzed with the nonlinear mixed model approach: (a) warmth, contingent responsiveness, positive affect, scaffolding, verbal encouragement, and restrictiveness for mother; (b) words, positive and negative affect for infant with mother; and (c) cooperation, negative affect for infant with examiner (SAS Macro GLIMMIX; SAS Institute, 1999). Because it was necessary to use different types of mixed models, comparison of parameter estimates should not be made because they are not equivalent. For this reason, to evaluate the magnitude of importance, one can use the effect size, a measure that is not unit dependent, to interpret the significance of results.

Approach used for testing effects of biological risk and context (Objective 2). The next step was to determine whether the growth parameters varied by the three between-groups factors used to predict change in mother and infant behaviors: study condition (PALS vs. DAS); infant risk group (term, low risk-VLBW, high risk-VLBW); context (toy play, daily activities); and the Intervention $\times$ Risk Group, Intervention $\times$ Context, Risk Level $\times$ Context, and Intervention $\times$ Risk Level $\times$ Context interactions. Context was included in the models to determine whether the results were consistent across situations in which the mother and infant interacted. Because our study objectives did not include hypotheses regarding the main effects for risk and context, these main effects and their interaction are not reported. However, significant interactions of these variables with intervention condition are included. To simplify models, we eliminated nonsignificant interactions and reexamined the model.

Assessment of clinical significance. To evaluate the clinical significance of the intervention effects, we report effect sizes as Cohen's $d$ (Cohen, 1988). This statistic is determined by obtaining the differences between groups divided by the square root of the random variance parameter and has the advantage of not depending on the degrees of freedom for the model (Raudenbush \& Liu, 2001). When the random variance for the slope was not significant (e.g., maternal physical intrusiveness, infant independent goaldirected play skills), a traditional effect size could not be obtained. In these cases, an approximation was obtained by comparing the change over 6-12 months with the variability in the parameter estimate size in order to provide information regarding the magnitude of change relative to the level of the variable. The practical significance of changes of $d=0.20$ are considered small, the practical significance of changes of $d=0.50$ are considered moderate, and the practical significance of changes of $d=0.80$ are considered large.

\section{Evidence of the Intervention Effectiveness (Objectives 1} and 2)

Data analyses for maternal behaviors are summarized in Table 2 and for infant behaviors in Table 3. The test of the omnibus effect, $F$ test, that evaluates for differences between conditions are provided in these two tables. When the results of $t$ tests are comparable with the omnibus test (i.e., there is only one degree of freedom), these are not reported. However, when the omnibus test for interactions between the parameter estimates and risk are significant, $t$ tests are reported, as they provide unique information.

Change in maternal behaviors. Because the intervention was expected to result in more optimal changes for a range of maternal behaviors associated with responsiveness in the literature, we first evaluated for changes in individual behaviors within each of the four aspects of responsiveness (Hypothesis 1a). Mothers' behaviors within all aspects of responsiveness in the intervention group changed more than in the comparison group and, generally, this was true across risk groups and social context. 
Table 2

Analyses of Change in Targeted Mother Behaviors

\begin{tabular}{|c|c|c|c|c|c|}
\hline \multirow[b]{2}{*}{ Variable } & \multicolumn{2}{|c|}{ Parameter estimate } & \multirow[b]{2}{*}{$d f \mathrm{~s}$} & \multirow[b]{2}{*}{$F$} & \multirow[b]{2}{*}{$p$} \\
\hline & PALS & DAS & & & \\
\hline \multicolumn{6}{|c|}{ Contingent responsiveness $_{\mathrm{a}}$} \\
\hline PALS vs. DAS & 0.77 & 0.99 & 1,1207 & 33.33 & .001 \\
\hline Slope $^{+}$ & & & 1,234 & 4.32 & .04 \\
\hline Slope $\times($ PALS vs. DAS $)$ & -0.04 & -0.02 & 1,1207 & 10.44 & .001 \\
\hline \multicolumn{6}{|c|}{ Emotional support } \\
\hline \multicolumn{6}{|l|}{ Warm sensitivity $_{\mathrm{a}}$} \\
\hline PALS vs. DAS & 0.74 & 0.90 & 1,1209 & 14.93 & .0001 \\
\hline Positive affect $_{\mathrm{a}}$ & & & & & \\
\hline (PALS vs. DAS) $\times$ Risk Group & & & 2,1434 & 4.52 & .02 \\
\hline Term & 0.77 & 0.70 & & & \\
\hline Low risk & 0.77 & 0.98 & & & \\
\hline High risk & 0.97 & 0.62 & & & \\
\hline \multicolumn{5}{|l|}{ Harshness of voice tone ${ }_{a}$} & .02 \\
\hline \multicolumn{6}{|l|}{ Physical intrusiveness $\mathrm{a}_{\mathrm{a}}$} \\
\hline PALS vs. DAS & 0.44 & 0.51 & 1,1439 & 6.94 & .01 \\
\hline Slope $\times($ PALS vs. DAS $) \times$ Risk Group & & & 2,1439 & 3.70 & .02 \\
\hline Term & -0.02 & 0.01 & & & \\
\hline Low risk & 0.01 & -0.01 & & & \\
\hline High risk & 0.00 & 0.03 & & & \\
\hline \multicolumn{6}{|l|}{ Restrictiveness } \\
\hline$($ PALS vs. DAS) $\times$ Risk Group & & & 2,1264 & 7.42 & .0001 \\
\hline Term & 0.69 & 0.41 & & & \\
\hline Low Risk & 0.64 & 0.72 & & & \\
\hline High Risk & 0.39 & 0.91 & & & \\
\hline Slope $^{+}$ & & & 1,233 & 21.74 & .0001 \\
\hline Slope $\times($ PALS vs. DAS $) \times$ Risk Group & & & 2,1264 & 3.38 & .03 \\
\hline Term & 0.07 & 0.04 & & & \\
\hline Low risk & 0.05 & 0.04 & & & \\
\hline High risk & -0.00 & 0.08 & & & \\
\hline
\end{tabular}

Responses to infant foci of attention

\begin{tabular}{|c|c|c|c|c|c|}
\hline \multicolumn{6}{|l|}{ Maintaining } \\
\hline PALS vs. DAS & 13.21 & 12.40 & 1,1261 & 3.21 & .08 \\
\hline Slope $^{+}$ & & & 1,237 & 8.33 & .01 \\
\hline Slope $\times($ PALS vs. DAS $)$ & -0.19 & -0.39 & 1,1261 & 3.91 & .05 \\
\hline \multicolumn{6}{|l|}{ Redirecting } \\
\hline PALS vs. DAS & 1.14 & 1.57 & 1,1263 & 39.89 & .0001 \\
\hline Slope $\times($ PALS vs. DAS $)$ & -0.03 & 0.00 & 1,1263 & 5.01 & .03 \\
\hline \multicolumn{6}{|c|}{ Quality of language input } \\
\hline \multicolumn{6}{|l|}{ Verbal scaffolding } \\
\hline PALS vs. DAS & 0.41 & -0.08 & 1,1261 & 20.57 & .0001 \\
\hline Slope $^{+}$ & & & 1,237 & 5.89 & .02 \\
\hline Curvature (quadratic term) & & & 1,237 & 6.40 & .01 \\
\hline Curvature $\times$ (PALS vs. DAS $)$ & -0.02 & 0.00 & 1,1261 & 7.45 & .01 \\
\hline \multicolumn{6}{|l|}{ Labeling objects $\mathrm{b}_{\mathrm{b}}$} \\
\hline PALS vs. DAS & -5.47 & -5.86 & 1,1226 & 18.86 & .0001 \\
\hline Slope $^{+}$ & & & 1,230 & 203.21 & .0001 \\
\hline Slope $\times($ PALS vs. DAS $)$ & 0.26 & 0.23 & 1,1226 & 3.44 & .06 \\
\hline \multicolumn{6}{|l|}{ Labeling actions $_{\mathrm{b}}$} \\
\hline PALS vs. DAS & -8.94 & -9.20 & 1,1223 & 12.04 & .0001 \\
\hline Slope $^{+}$ & & & 1,228 & 126.36 & .0001 \\
\hline Curvature & & & 1,228 & 17.83 & .0001 \\
\hline Curvature $\times($ PALS vs. DAS $)$ & -0.02 & 0.00 & 1,1223 & 4.23 & .05 \\
\hline \multicolumn{6}{|l|}{ Verbal encouragement } \\
\hline PALS vs. DAS & 0.67 & 0.24 & 1,1263 & 18.61 & .0001 \\
\hline
\end{tabular}

Note. For all analyses, the intercept parameter is random, and slope and curvature parameters are random unless otherwise indicated as a fixed effect by ${ }^{+}$. Degrees of freedom vary because of the number of terms in each of the models. Lower parameters for behaviors coded as ratings $\left(_{\mathrm{a}}\right.$ ) or scaled variables $\mathrm{(}_{\mathrm{b}}$ ) indicate a better score. PALS $=$ playing and learning strategies; DAS $=$ developmental assessment screening. 
Table 3

Analyses of Change in Infant Behaviors

\begin{tabular}{|c|c|c|c|c|c|}
\hline \multirow[b]{2}{*}{ Variable } & \multicolumn{2}{|c|}{ Parameter estimate } & \multirow[b]{2}{*}{$d f \mathrm{~s}$} & \multirow[b]{2}{*}{$F$} & \multirow[b]{2}{*}{$p$} \\
\hline & PALS & DAS & & & \\
\hline \multicolumn{6}{|c|}{ Interactions with mother } \\
\hline \multicolumn{6}{|l|}{ Social skills: Cooperation } \\
\hline PALS vs. DAS & 5.56 & 5.16 & 1,1261 & 3.24 & .08 \\
\hline Slope $^{+}$ & & & 1,235 & 11.83 & .001 \\
\hline Slope $\times($ PALS vs. DAS $)$ & 0.32 & 0.23 & 1,1261 & 3.00 & .08 \\
\hline \multicolumn{6}{|l|}{ Early communication: Words } \\
\hline Slope $^{+}$ & & & 1,237 & 34.96 & .0001 \\
\hline Slope $\times($ PALS vs. DAS $)$ & 0.26 & 0.11 & 1,1258 & 5.78 & .02 \\
\hline Curvature (quadratic term) & & & 1,237 & 20.34 & .0001 \\
\hline Curvature $\times$ (PALS vs. DAS $)$ & -0.05 & -0.02 & 1,1258 & 6.14 & .02 \\
\hline Curvature (cubic term) & & & 1,237 & 5.65 & .02 \\
\hline Curvature $\times($ PALS vs. DAS $)$ & 0.00 & 0.01 & 1,1258 & 6.44 & .02 \\
\hline \multicolumn{6}{|l|}{ Affect: Negative } \\
\hline$($ PALS vs. DAS $) \times$ Risk Group & & & 2,1250 & 6.90 & .001 \\
\hline Term & 0.54 & -0.10 & & & \\
\hline Low risk & 0.02 & -0.24 & & & \\
\hline High risk & -0.27 & 0.49 & & & \\
\hline$($ PALS vs. DAS $) \times$ Risk Group $\times$ Context & & & 2,1250 & 4.07 & .02 \\
\hline \multicolumn{6}{|l|}{ Toy play } \\
\hline Term & 0.68 & 0.17 & & & \\
\hline Low risk & 0.43 & 0.30 & & & \\
\hline High risk & 0.45 & 0.53 & & & \\
\hline Slope $\times($ PALS vs. DAS $)$ & 0.08 & -0.04 & 1,1250 & 3.88 & .05 \\
\hline \multicolumn{6}{|c|}{ Interactions with examiner } \\
\hline \multicolumn{6}{|l|}{ Social skills: cooperation } \\
\hline$($ PALS vs. DAS $) \times$ Risk Group & & & 2,913 & 3.69 & .03 \\
\hline Term & -4.24 & -3.78 & & & \\
\hline Low risk & -3.22 & -3.94 & & & \\
\hline High risk & -4.26 & -3.73 & & & \\
\hline Slope & & & 1,913 & 25.20 & .0001 \\
\hline Slope $\times($ PALS vs. DAS $) \times$ Risk Group & & & 2,913 & 2.48 & .08 \\
\hline Term & 0.31 & 0.41 & & & \\
\hline Low risk & 0.60 & 0.34 & & & \\
\hline High risk & .027 & 0.21 & & & \\
\hline \multicolumn{6}{|l|}{ Early communication: Words } \\
\hline Slope $\times($ PALS vs. DAS $)$ & 0.14 & -0.07 & 1,662 & 6.17 & .02 \\
\hline \multicolumn{6}{|l|}{ Affect: Negative } \\
\hline PALS vs. DAS & -0.07 & 0.28 & 1,425 & 6.99 & .008 \\
\hline \multicolumn{6}{|c|}{ Independent goal-directed play } \\
\hline Slope $^{+}$ & & & 1,720 & 55.56 & .0001 \\
\hline Slope $\times($ PALS vs. DAS $)$ & 0.65 & 0.36 & 1,720 & 4.56 & .04 \\
\hline
\end{tabular}

Note. For all analyses, the data are frequencies, and the intercept parameter is random. Slope and curvature parameters are random unless indicated as a fixed effect by ${ }^{+}$. Degrees of freedom vary because of the number of terms in each of the models. PALS = playing and learning strategies; DAS $=$ developmental assessment screening.

Contingent responsiveness. As illustrated in Figure 1, responses to children's signals and learning needs that were prompt, contingent, and appropriate were different across intervention versus comparison mothers. Mothers in the PALS condition showed significantly higher levels at the end of the intervention $(d=0.93)$ as well as greater increases $(d=0.85)$ in their use of contingent responsiveness when interacting with their infants when compared with mothers in the DAS condition.

Emotional-affective support. Higher levels of warm sensitivity were found for mothers in the PALS compared with the DAS condition $(d=0.49)$. Higher levels, $t(1434)=2.54, p<.01, d=$ 0.83 , and greater increases, $t(1434)=2.51, p<.01, d=0.22$, in positive affect also were found for mothers in the PALS versus DAS conditions but only for those parenting infants who were born low risk-VLBW. Contrary to expectations, mothers of infants born high risk-VLBW in the DAS condition displayed higher levels of smiling and laughing with their infants, $t(1434)=-2.85$, $p<.01, d=0.55$, than those in the PALS condition.

The intervention also had positive effects on how frequently mothers used negative interactive behaviors, as mothers in the 

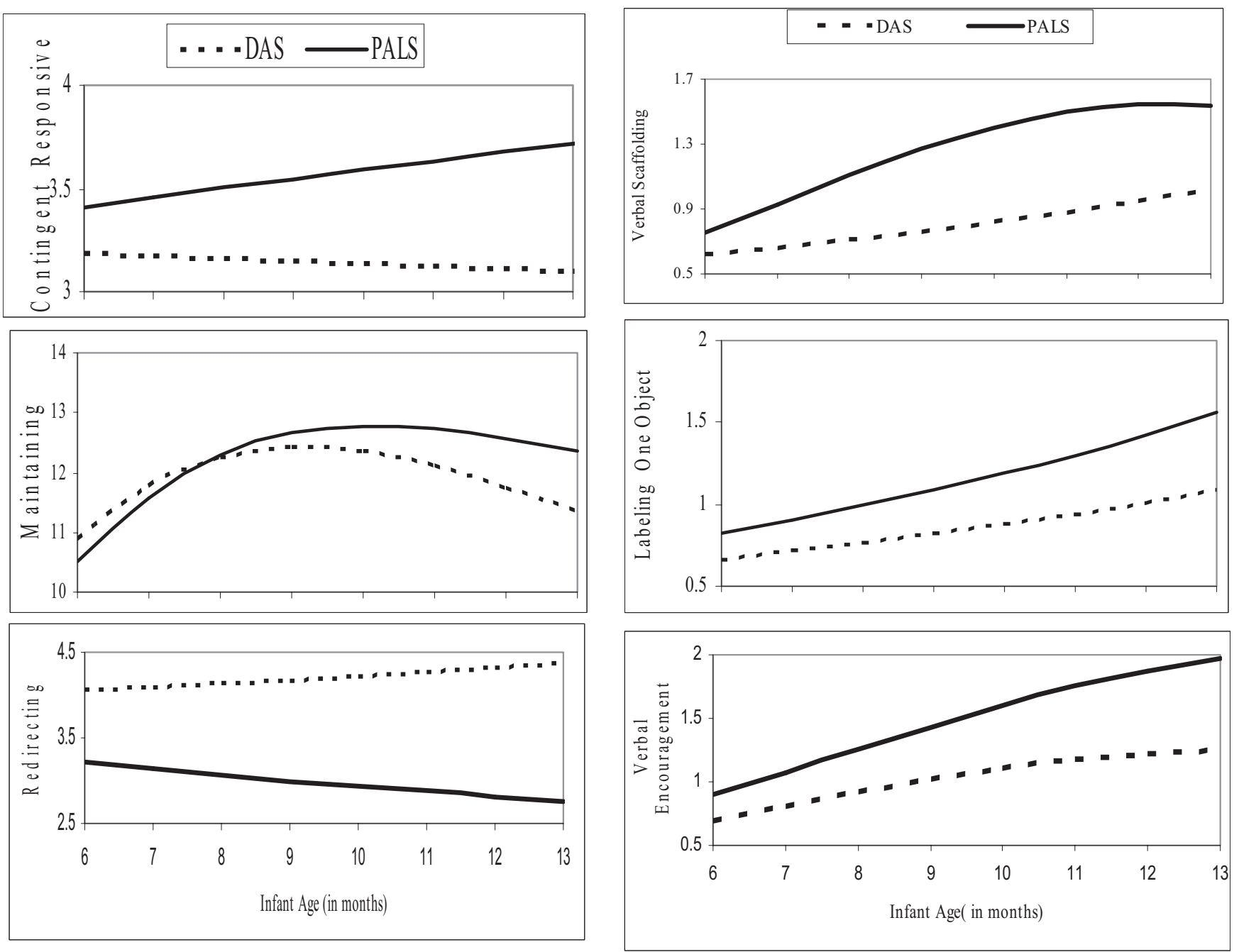

Figure 1. Change in ratings of mothers' contingent responsiveness (based on 5-point scale) and frequency of maintaining, redirecting, verbal scaffolding, labeling objects, and verbal encouragement for intervention (PALS) versus comparison (DAS) conditions collapsed across risk group and context. PALS = playing and learning strategies; DAS = developmental assessment screening.

DAS versus the PALS condition showed significantly higher levels of a harsh voice tone $(d=0.28)$ and lower levels of physical intrusiveness $(d=0.50)$. Less of an increase in physical intrusiveness also was found, but this was most apparent for mothers in the PALS condition parenting infants born high risk-VLBW, $t(1439)=2.44, p<.02, d=0.45$, or at term, $t(1439)=2.23, p<$ $.03, d=0.33$, compared with those parenting infants born low risk-VLBW.

A significant Intervention $\times$ Biological Risk interaction was found for level and rate of change in the use of restricting behaviors. Mothers in the PALS compared with the DAS condition with infants born high risk-VLBW used this behavior at significantly lower levels, $t(1264)=-3.23, p<.001, d=1.23$, and showed significantly slower rates of increases, $t(1264)=-2.34, p<.02$, $d=1.34$. Contrary to expectations, mothers of infants born at term in the PALS condition used restricting behaviors at a significantly higher level than those in the DAS condition, $t(1264)=2.12, p=$ $.03, d=0.65$.
Support of infant foci of attention. Mothers in the PALS compared with the DAS condition showed significantly higher levels of maintaining at the intervention completion $(d=0.36)$ as well as greater increases $(d=0.65$; see Figure 1$)$. Redirecting, a behavior unresponsive to children's signals, was used at significantly lower levels by mothers in the PALS compared with the DAS condition $(d=1.31)$. Mothers in the PALS condition also showed a greater decline in this behavior $(d=0.66)$.

Quality of language input. Significant intervention effects were found for all language variables (see Figure 1). Mothers in the PALS compared with the DAS conditions used higher levels of verbal scaffolding $(d=0.79)$. Although mothers in the PALS condition showed a greater deceleration in this behavior by the final assessment, their use of verbal scaffolding at 12 months remained almost twice that of those in the DAS condition. Mothers in the PALS condition also used significantly higher levels in their labeling of objects $(d=0.71)$ and a trend for greater increases $(d=0.43)$. Mothers in the PALS condition also showed higher 
levels of labeling actions $(d=0.63)$. In spite of greater deceleration for mothers in the PALS condition, their use of action labels remained significantly greater. The intervention also influenced verbal encouragement, as mothers in the PALS condition showed higher levels than those in the DAS condition $(d=0.71)$.

Change in infant behaviors with mothers. A major objective of this study was to determine whether there was evidence for a causal influence of responsiveness behaviors on infant development (Hypothesis 1b; see Table 3 and Figure 2). In light of greater changes for the target in contrast to the comparison mothers' responsiveness behaviors, we could evaluate this hypothesis by examining whether the target infant skills showed greater improvements when contrasted to the comparison infants. Analyses addressing the extent to which responsiveness behaviors differentially impacted the development of infants of varying characteristics also were evaluated (Hypothesis 2). In general, greater changes were found in infant behaviors for those with mothers in the PALS versus DAS condition across skill domains, measured from mother-infant interactions. The intervention showed differential effects related to risk status but only for decreased expression of negative affect for the high risk-VLBW infants. The changes for each of the four developmental domains are described below.

Early communication. Infants whose mothers were in the PALS compared with the DAS condition demonstrated significantly greater increases in their use of words $(d=0.75)$. Although the rate of increase was decelerating more for these infants than those in the DAS condition, they remained significantly higher in word usage.

Social cooperation. Infants of mothers in the PALS versus DAS condition showed a trend for higher levels $(d=0.39)$ and greater increases $(d=0.50)$ in their cooperation, and these trends were apparent across both contexts.
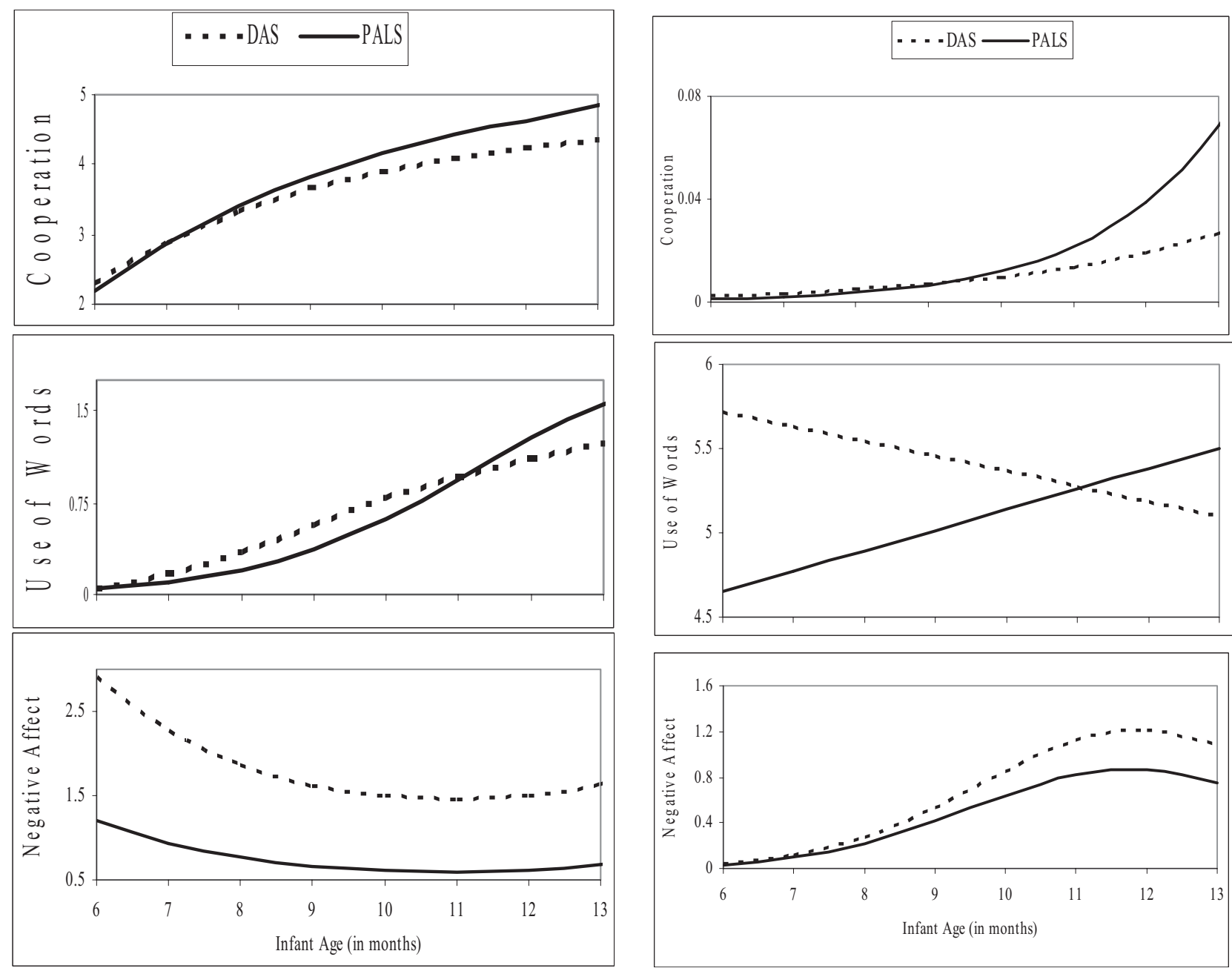

Figure 2. Change in infant behaviors for intervention (PALS) versus comparison (DAS) conditions when interacting with their mothers (left panels) and examiner (right panels). All panels of infant behavior with mother are collapsed across risk group and context, with the exception of negative affect, during toy play with mother for high risk-very low birth weight group only (bottom left panel). All infant behaviors with examiner are collapsed across risk group, with the exception of infant cooperation, for low risk-very low birth weight group only (top right panel). PALS = playing and learning strategies; DAS $=$ developmental assessment screening. 
Affect. When infants interacted with their mothers, negative affect was significantly lower at the end of the intervention, but this was particularly apparent for the infants born high riskVLBW whose mothers were in the PALS condition compared with those born high risk-VLBW whose mothers were in the DAS condition, $t(395)=-3.34, p<.001, d=0.91$, and only in the toy play context.

Generalization of increased infant skills with a novel adult. In order to determine whether the target versus comparison infants also could show more optimal skills in interactions with responsive adults other than their mother, we evaluated their growth in skills when interacting with a novel adult (Hypothesis 1c; see Table 3 and Figure 2). Positive findings would support the notion that increased responsiveness provides a secure foundation for infants to begin to develop skills to regulate their own behavior outside of mothers' presence. As predicted, infants with mothers in the PALS compared with the DAS condition showed higher levels or greater gains in skills in this situation (Hypothesis 1c). A differential impact of the intervention for generalization with a novel adult by infant risk group was only found for social cooperation (Hypothesis 2).

Early communication. Infants with mothers in the PALS compared with the DAS condition showed a significantly greater increase in the use of words in interactions with the examiner, and this was true across risk groups $(d=0.22)$.

Social cooperation. A significant Intervention $\times$ Infant Risk Group interaction for cooperation was found for level and slope. These analyses revealed that the infants born low risk-VLBW with mothers in the PALS condition had a higher level of cooperation than those with mothers in the DAS condition, $t(913)=2.03, p<$ $.04, d=0.45$, and showed greater increases, $t(913)=2.06, p<$ $.04, d=0.20$.

Affect. Greater gains for infants with mothers in the PALS versus DAS conditions were apparent. Infants with mothers in the DAS condition displayed higher levels of negative affect in the interaction with the examiner $(d=0.70)$.

Change in infant independent problem solving (Hypothesis 1d). A second situation that evaluated for differences in infants' skills across the two study conditions when they were not interacting with their mothers was an independent goal-directed play activity (see Table 3). Using a range of toys, infants whose mothers were in the PALS condition showed greater increases in more complex play skills than those with mothers in the DAS condition $(d=0.47)$.

\section{Objective 3: Evaluate Whether Different Aspects of Responsiveness Mediate the Intervention Impact on Domains of Infant Development}

Before determining whether different aspects of responsiveness mediated the effectiveness of the intervention on different infant skills, we conducted an exploratory principle-axes factor analyses with a Promax oblique rotation. This approach examines for underlying factors of a construct when inadequate information is available to confirm a hypothesized structure (Preacher \& MacCallum, 2003). Correlational analyses were then conducted to determine the extent of the relation among the factors identified in order to determine whether there was support for the factors being part of a responsiveness construct.

Once empirical support was found for the presence of different behaviors contributing to the construct of responsiveness, the next step was to determine whether different aspects of responsiveness promoted gains in infant skills (Hypothesis 3a). The presence of significant mediation effects provides additional support for the causal influence of increases in responsiveness on gains in infant development. To demonstrate a mediating effect, we met two criteria: (a) the intervention condition had expected effects on changes in the selected maternal behaviors and infant outcomes, and (b) the significance and parameter estimates (i.e., intercept, Intervention $\times$ Slope) of the intervention condition are reduced when the maternal behaviors are included as time-varying covariates in the model (Baron \& Kenny, 1986).

To determine which maternal behaviors would be included in the mediation models for each of the three infant skills, we examined a pooled estimate of regression coefficients across the four time points to determine for significance between maternal variables and infant outcomes. Only those maternal variables that significantly related to the infant behavior at $p<.05$ were included in the mediation models. In order to determine whether VLBW status moderated the mediational effects, we included infant risk status as a potential moderator in the analyses (Hypothesis 3b).

Empirical support for four aspects of responsiveness. In general, stability for the factor structure summarized in Table 4 was found for both contexts (daily activities, toy play). The estimate of the total common variance across the 12 variables was $51.4 \%$ in the daily activities context and $54.4 \%$ in toy play, and the results revealed consistency in factor structure across pre- to follow-up assessments. Results revealed four factors that correspond to four aspects of responsiveness described in conceptual frameworks in the literature: (a) contingent responsiveness-lack of negative emotionality, (b) positive emotional support, (c) responses to infant foci of attention, and (d) quality of language input. A difference in factor structure across contexts was found for behaviors representing mothers' contingent responsiveness. In daily activities, it loaded with negative emotionality, whereas in toy play, it loaded with redirecting. Also, verbal encouragement loaded on a separate factor in toy play but loaded with positive response to infant foci of attention (maintaining) in daily activities.

Examination of the relations among the factors revealed small to high correlations (see Table 5), providing some support for the factors to be considered part of an overarching responsiveness construct. For example, the factor involving negative responses to the infant foci of attention (redirecting) in the daily activities context demonstrated moderate intercorrelations with all other factors (range: $r=-.31$ to -.47 ). One factor less related to the other factors was positive response to infant foci of attention (maintaining), but this was only true in the toy play context.

The link between maternal responsiveness and infant development. The mediating effect of maternal behaviors on gains in the three infant skills that showed positive change in interactions with mother were examined: social (infant cooperation), early communication (word use), and negative affect. For infant cooperation, significant relations were found among contingent responsiveness, maintaining, redirecting, labeling objects, verbal scaffolding, verbal encouragement, restrictiveness, and warmth. However, only contingent responsiveness, $F(1,1194)=15.17, p<.0001$, verbal encouragement, $F(1,1194)=54.76, p<.0001$, and restrictiveness, $F(1,1194)=6.33, p<.02$, were significant mediators when the intervention condition was included in the model. Given that the intervention effect was no longer significant for the level or the 
Table 4

Factor Structure for the Responsiveness Behaviors by Context

\begin{tabular}{|c|c|c|c|c|c|c|c|c|c|c|c|}
\hline \multirow[b]{2}{*}{ Variable } & \multicolumn{5}{|c|}{ Daily activity } & \multicolumn{6}{|c|}{ Toy play } \\
\hline & 1 & 2 & 3 & 4 & 5 & 1 & 2 & 3 & 4 & 5 & 6 \\
\hline Restrictiveness & -0.76 & 0.10 & -0.00 & 0.23 & 0.00 & -0.87 & 0.08 & 0.04 & 0.04 & -0.04 & 0.17 \\
\hline Less physical intrusiveness & 0.75 & 0.09 & -0.17 & 0.07 & 0.01 & 0.44 & 0.05 & -0.09 & 0.39 & -0.09 & 0.20 \\
\hline Less harsh voice tone & 0.83 & -0.11 & 0.00 & -0.07 & 0.17 & 0.89 & 0.03 & 0.00 & -0.14 & 0.00 & -0.03 \\
\hline Contingent responsiveness & 0.41 & 0.04 & 0.11 & 0.20 & -0.38 & 0.17 & -0.02 & 0.26 & 0.59 & -0.04 & 0.08 \\
\hline Redirecting & 0.12 & 0.08 & 0.12 & 0.06 & 0.75 & 0.13 & 0.02 & 0.17 & -0.73 & -0.04 & 0.03 \\
\hline Warm sensitivity & 0.20 & 0.11 & 0.50 & 0.26 & -0.05 & 0.11 & 0.06 & 0.58 & 0.12 & 0.18 & 0.10 \\
\hline Positive affect & -0.16 & -0.06 & 0.78 & -0.07 & 0.13 & -0.11 & -0.02 & 0.84 & -0.16 & -0.08 & 0.00 \\
\hline Maintaining & -0.15 & -0.15 & -0.02 & 0.61 & .05 & -0.11 & -0.04 & 0.05 & 0.03 & 0.09 & 0.36 \\
\hline Verbal encouragement & 0.02 & 0.21 & -0.01 & 0.40 & -0.04 & 0.00 & 0.02 & -0.03 & 0.02 & 0.66 & 0.12 \\
\hline Labeling objects & 0.05 & 0.80 & 0.00 & -0.06 & 0.05 & -0.01 & 0.56 & 0.04 & 0.15 & 0.10 & -0.21 \\
\hline Labeling actions & -0.08 & 0.79 & 0.06 & -0.24 & -0.11 & -0.03 & 0.72 & 0.04 & 0.09 & -0.05 & -0.18 \\
\hline Verbal scaffolding & -0.06 & 0.64 & -0.12 & 0.26 & 0.17 & 0.02 & 0.79 & -0.06 & -0.18 & 0.00 & 0.25 \\
\hline
\end{tabular}

Note. Data are rotated factor patterns at preassessment. The numbers under Daily activity and Toy play were identified in a factor analysis. Boldface indicates variables that contribute more to the variance of that factor.

degree of growth in cooperation, complete mediation was found. The intercept estimate for the intervention was reduced by $110 \%$ and for the slope by $62 \%$. Biological risk did not moderate this mediation effect.

Significant relations between maternal behaviors and infants' growth in use of words were found for contingent responsiveness, maintaining, labeling objects, scaffolding, and warmth. However, only maintaining, $F(1,365)=23.21, p<.0001$, and labeling, $F(1$, $367)=3.58, p<.05$, remained predictive of growth in word use when the intervention condition was included in the model. With the two responsive behaviors included in the model, the intervention effect was decreased by $29 \%$, indicating a partially mediated effect. The mediation effect of maintaining on growth in word use was moderated by infant birth status, with the relation stronger for infants born at term compared with infants born at VLBW, $t(1257)=2.45, p<.02$.
Significant relations between infant affect and maternal behaviors included contingent responsiveness, maintaining, redirecting, verbal scaffolding, verbal encouragement, physical intrusiveness, restrictiveness, warmth, and harshness of voice tone. However, when these were entered into a model with the intervention condition, they did not remain significant.

\section{Discussion}

Responsive parenting has long been considered critically important for promoting a broad range of infant skills. However, its importance, to date, is based on descriptive studies, and thus evidence for a causal role of responsiveness in promoting more optimal child development is limited. A major study objective was to provide support for this causal role with an experimental approach evaluating changes in a range of maternal responsive

Table 5

Correlations Among the Responsiveness Factors by Context

\begin{tabular}{lrrrrrr}
\hline \multicolumn{1}{c}{ Variable } & 1 & 2 & 3 & 4 & 5 & 6 \\
\hline \multicolumn{1}{c}{ Daily activity } & & & & & \\
& & & & & \\
1. Contingent responsiveness-negative emotional support & - & & & & \\
2. Quality of language input & -0.03 & - & & & \\
3. Positive emotional support & 0.41 & 0.23 & - & & \\
4. Positive responses to infant foci of attention & 0.23 & 0.40 & 0.52 & - & \\
5. Negative responses to infant foci of attention & -0.45 & -0.31 & -0.47 & -0.45 & - \\
\hline
\end{tabular}

Toy play

1. Contingent responsiveness-negative emotional support

2. Quality of language input

3. Positive emotional support

4. Positive responses to infant foci of attention

5. Negative responses to infant foci of attention

6. Verbal encouragement

\begin{tabular}{rrrrrr}
$\overline{0.35}$ & \multicolumn{1}{c}{-} & & & \\
0.33 & -0.11 & - & & \\
0.46 & 0.38 & 0.19 & - & \\
0.15 & -0.13 & 0.26 & 0.10 & - \\
0.45 & 0.46 & 0.08 & 0.54 & -0.10 & -
\end{tabular}

Note. Data are factor patterns at preassessment. Using Fisher's $r$ to $z$ transform, all correlations are greater than $.19, p<.01$. 
behaviors with growth in infant skills. It also sought to determine whether infants who varied in biological risk benefited in comparable ways. This would provide support for the effectiveness of responsive parenting to be due, in part, to its sensitivity to individual needs. However, the strongest test of a causal influence was expected to come from the demonstration that aspects of maternal responsiveness mediated the intervention effect on infant behaviors. For this final objective, we were particularly interested in whether the multiple aspects of responsiveness described in the literature could be identified empirically and together would support different domains of infant development.

\section{Objective 1: Determine Whether Changes in a Range of Maternal Responsiveness Behaviors Result in Increases in Infant Skills}

The intervention facilitated target mothers' ability to increase their use of the range of behaviors identified in the literature as associated with responsive parenting (Hypothesis 1a). Four aspects of responsiveness were targeted with these mothers who, together, were found to support greater increases in their infants' social, communicative, and affective skills with moderate to strong effect sizes (Hypothesis 1b). Increased infant competence was thought to occur because of the steady increases the target mothers showed in their responses that were prompt, sensitive, and contingent to their infants' signals as well as in their use of rich language input. Such changes suggest that target mothers were appreciating their infants' positive and negative signals as communication of specific needs and interests. In contrast, the infants of comparison mothers experienced decreases in contingent responsiveness, increases in intrusiveness, restrictions, and harsher voice tones, and more limited language input, and their infants showed less growth in their skill development.

Increases in responsive language input from lower educated mothers is an encouraging finding, as changing this behavior may not be consistent with their cultural and community backgrounds (e.g., Heath, 1989). Across this early period of emerging language, the target infants across all risk groups showed greater growth in their use of words, whereas the comparison infants' developmental trajectory was less steep (see Figure 2). This type of language input infrequently occurs in families of low education (Hart \& Risley, 1995), and initially many target mothers said that they did not understand the importance of talking to their infants and had difficulty in knowing what to say when infants did not talk back to them.

Increases in target versus comparison infants' cooperation, an early social skill, paralleled mothers' increases in responsive caregiving (e.g., contingent responsiveness, warmth, decreased negativity). In contrast, with less attention to infant signals, poorer language input, and less emotional support, the comparison infants' cooperation leveled off across the study period. This is consistent with research demonstrating children's greater willingness to cooperate in the presence of caregiving styles that promote give and take and sharing of control (Grusec \& Goodnow, 1994; Parpal \& Maccoby, 1985). The process that underlies the effectiveness of responsiveness includes allowing children some control that, in turn, is thought to enhance a positive mood and greater cooperative behavior.
Together, the pattern of changes in this experimental study for the target in contrast to the comparison mothers indicated a shift in the range of behaviors thought to be reflective of responsiveness. The growth in the target infants' skills appeared to mirror this shift and thus provides support for a causal role for responsiveness on infant development. In contrast, the lower levels and/or slower rates of growth of the comparison infants are attributed to the minimal or negative change in responsiveness by their mothers.

\section{Evidence for Enhanced Infant Skills to Generalize}

The provision of responsive caregiving is not only thought to support infant skill development when infants are interacting with their caregivers but also to assist infants' ability to develop the resources necessary to cope with stress and novelty. This is expected to occur through the process of internalization in which infants begin to learn to regulate their own behaviors without the direct responsive support of their caregivers (Ainsworth et al., 1978; Bornstein \& Tamis-LeMonda, 1989). Our study directly tested for evidence of internalization in two ways: through infants interacting with a novel adult, a situation expected to be more stressful than with their mothers, and the ability to independently organize their behaviors with toys. All infants with mothers in the target condition demonstrated greater increases in their use of words and strong changes in their regulation of affect with the examiner (Hypotheses 1c and d). However, changes with the examiner were often smaller or only evident for a specific risk group. The greater support the target infants received from their mothers for their immature attentional and regulatory skills may have facilitated better behavioral organization so that they could respond without high degrees of negative affect.

Evidence for infants' ability to internalize newly developed skills also was found in the target infants' greater ability to independently use toys in goal-directed and functional ways. As the two groups of infants were comparable in their exploratory play skills on the initial evaluation, the target infants' greater skill when solving problems may have its origin in shared engagement that involves higher levels of responsiveness (Vygotsky, 1978). These results support theories suggesting that increasing competence in the presence of supportive others provides a foundation for learning in independent problem-solving situations (Bruner, 1972; Wertsch, 1979).

\section{Objective 2: Determine Whether There Is Differential Effectiveness of Responsiveness for Varying Infant Characteristics}

Given the special needs of children born at VLBW, particularly in infancy, our findings highlight an important aspect of responsiveness concerning its attention and support for meeting infants' individual needs. In general, all aspects of the target mothers' responsiveness supported the development of infants born at VLBW to the same or greater extent as those born at term (Hypothesis 2). In one domain, negative affect, the infants born at VLBW with more severe neonatal complications were more likely than the other two infant groups to display a greater reduction in behaviors such as crying and fussing if their mothers were in the target condition. This may have occurred, in part, because the maternal support provided was particularly helpful to the affective 
regulation for these more vulnerable infants who are frequently reported to show higher levels of negative affect and behavioral dysregulation (Goldberg et al., 1989). It is further encouraging that in the presence of a novel adult, the infants born at VLBW in the target group were just as likely to show positive changes as the healthy, term infants in this group.

\section{Objective 3: Evaluate Whether Different Aspects of Responsiveness Mediate the Intervention Impact on Domains of Infant Development}

Support for four aspects of responsiveness. Empirical support was found for four related factors that correspond to the four aspects of responsiveness identified in conceptual frameworks in the literature that were stable over time and, in general, across contexts. The significant correlations among the factors in the daily activities context provided evidence that although there are unique aspects of responsiveness, they share common variance and thus might be considered as part of a general responsiveness construct. As expected, the factor structure revealed that responsive behaviors, typically described within a theoretical framework, were in the same factor, although those described as being in different frameworks were rarely found on the same factor. For example, contingent responsiveness, although attentive and supportive of infant signals, was found to be distinct from maintaining infant foci of interest, and this may be related to their different hypothesized mechanisms of influence described in the attachment and sociocultural frameworks. Warmth and positive affect also compromised a distinct factor from that of the lack of negative affect and contingent responsiveness, supporting previous theoretical perspectives (e.g., MacDonald, 1992). Negative emotionality often is associated with secure attachment, which emphasizes acceptance and responsiveness to distress signals, although warmth has different biological origins and is often found to support positive engagement (Maccoby \& Martin, 1983).

The link between maternal responsiveness and infant development. Further support for a causal role of the responsiveness behaviors was found through the results of the mediation models for two of three infant outcome domains: cooperation and use of words (Hypothesis 3a), with use of words moderated by birth status (Hypothesis 3b). For cooperation, the picture that emerged was the need for aspects of responsiveness that cut across theoretical frameworks and thus provided different types of support, in order to support this early social skill. Feedback that is contingent on infant signals in sensitive ways, verbal encouragement that provides feedback about the infants' behavior, and decreased restricting of infant endeavors all were needed to fully explain growth in cooperation. The importance of these behaviors for cooperation has been described by parent socialization researchers (e.g., Parpal \& Maccoby, 1985). However, the ability of the three behaviors to completely explain the intervention effect on cooperation advances researchers' understanding of early social development by highlighting the importance of the infants' need for multiple aspects of responsive caregiving.

When we examined the effects of responsiveness on infants' words, a different picture emerged. Two behaviors consistently reported to influence children's word use, maintaining and labeling, partially mediated the intervention influence. Although warmth showed relations with this infant outcome, it did not remain significant when the effect of the intervention was added. The behaviors that were most important for understanding growth in word use were consistent with behaviors associated with the sociocultural framework, emphasizing the importance of the scaffolding of children's individual developmental needs.

Although the intervention appeared to be comparable in supporting the development of infants' word use irrespective of biological risk status, risk moderated the mediational effect of maintaining on word use, with maintaining being a stronger mediator for infants born at term versus infants born at VLBW. A number of descriptive studies with infants born at term reported a similar relation (Akhtar et al., 1991; Tomasello \& Farrar, 1986), but less is known about maintaining and word use for infants born at VLBW. As infants born at VLBW have less clear signals (Goldberg et al., 1989) and fewer shifts in looking at aspects of their environment (Landry \& Chapieski, 1988), it may be that mothers' attempts to use this strategy to support these infants' word use is less effective at this early age.

\section{Study Limitations}

When we considered study limitations, two differences were found across conditions: a greater proportion of female infants in the intervention versus the comparison group $(M=7 \%)$ and a longer duration of the intervention condition ( $M=1$ week). As gender was not found to moderate the intervention effects, it is unlikely that this difference explains the positive intervention findings. The longer duration of PALS versus DAS, due to scheduling of home visits with an alternate caregiver, may have resulted in PALS mothers having more time to practice the targeted behaviors. However, all mothers received the same number of visits in their homes and thus there was not a difference in the amount of attention given to mothers. Additionally, although there was a higher attrition rate for African American and other ethnicities, this was true across both study conditions. This differential attrition may be explained by a greater mobility of African American families, as that was the reason why most families left the study. Although the study demonstrates the potential impact of a responsive style on infant development in a socially high-risk population, the intervention was not developed as a comprehensive, multifaceted approach that may be required for families of the highest social risk (e.g., drug abuse, teenage mothers).

\section{Conclusions}

Given support for the causal influence documented in this study for the importance of responsiveness for infant development, the results have implications for parenting interventions. The influence of behaviors across four aspects of responsiveness on both cognitive and social-emotional outcomes also is consistent with conceptual frameworks defining responsiveness as a broad, rather than a narrow, construct. For parenting programs targeting either emotional nurturance of children's needs or stimulation of cognitive and language skills, these results indicate the need to incorporate a broader range of responsive behaviors into parent-infant interactions. It is recognized that the ultimate test of the influence of responsiveness on development would require evaluation of these infants into later ages to determine whether the positive influence persists. The positive effect of the intervention on rates of infant 
growth suggests that infant development across the two groups may become more divergent over time with a continued advantage for the target condition.

\section{References}

Ainsworth, M. D. S., Blehar, M., Waters, E., \& Wall, S. (1978). Patterns of attachment: A psychological study of the strange situation. Hillsdale, NJ: Erlbaum.

Akhtar, N., Dunham, F., \& Dunham, P. J. (1991). Directive interactions and early vocabulary development: The role of joint attention focus. Journal of Child Language, 18, 41-49.

Bakeman, R., \& Adamson, L. B. (1984). Coordinating attention to people and objects in mother-infant and peer-infant interactions. Child Development, 55, 1278-1289.

Bakeman, R., \& Brown, J. V. (1980). Early interaction: Consequences for social and mental development at three years. Child Development, 51, 437-447.

Bakermans-Kranenburg, M. J., van IJzendoorn, M. H., \& Juffer, F. (2003). Less is more: Meta-analyses of sensitivity and attachment interventions in early childhood. Psychological Bulletin, 129, 195-215.

Baron, R. M., \& Kenny, D. A. (1986). The moderator-mediator variable distinction in social psychological research: Conceptual, strategic, and statistical considerations. Journal of Personality and Social Psychology, $51,1173-1182$

Baumrind, D. (1989). Rearing competent children. In W. Damon (Ed.), Child development today and tomorrow (pp. 349-378). San Francisco: Jossey-Bass.

Bayley, N. (1993). Bayley scales of infant development (2nd ed.). San Antonio, TX: Psychological Corporation.

Beckwith, L., \& Rodning, C. (1992). Evaluating effects of intervention with parents of preterm infants. In S. Friedman \& M. Sigman (Eds.), The psychological development of low-birthweight children: Annual advances in applied developmental psychology (Vol. 6, pp. 389-410). Norwood, NJ: Ablex.

Bornstein, M., \& Tamis-LeMonda, C. S. (1989). Maternal responsiveness and cognitive development in children. In M. H. Bornstein (Ed.), Maternal responsiveness: Characteristics and consequences (pp. 49-61). San Francisco: Jossey-Bass.

Bruner, J. S. (1972). Nature and uses of immaturity. American Psychologist, 27, 687-708.

Bryk, A. S., \& Raudenbush, S. W. (1992). Hierarchical linear models: Applications and data analysis methods change. Newbury Park, CA: Sage.

Cohen, J. (1988). Statistical power analysis for the behavioral sciences (2nd ed.). Hillside, NJ: Erlbaum.

Darling, N., \& Steinberg, L. (1993). Parenting style as context: An integrative model. Psychological Bulletin, 113, 487-496.

Fenson, L., Kagan, J., Keasley, R. B., \& Zelazo, P. R. (1976). The developmental progression of manipulative play in the first two years. Child Development, 47, 232-236.

Fleiss, J. L. (1986). The design and analysis of clinical experiments. New York: Wiley.

Frick, T., \& Semmel, M. I. (1978). Observer agreement and reliabilities of classroom observational measures. Review of Educational Research, 48, $157-184$.

Goldberg, S., Grusec, J. E., \& Jenkins, J. M. (1999). Confidence in protection: Arguments for a narrow definition of attachment. Journal of Family Psychology, 13, 475-483.

Goldberg, S., Lojkasek, M., Gartner, G., \& Corter, C. (1989). Maternal responsiveness and social development in preterm infants. In M. H. Bornstein (Ed.), Maternal responsiveness: Characteristics and consequences (pp. 89-104). San Francisco: Jossey-Bass.

Grusec, J. E., \& Goodnow, J. J. (1994). Impact of parental discipline methods on the child's internalization of values: A reconceptualization of current points of view. Developmental Psychology, 30, 1-19.

Hardy-Brown, K., \& Plomin, R. (1985). Infant communicative development: Evidence from adoptive and biological families with genetic and environmental influences on rate differences. Developmental Psychology, 21, 378-385.

Hart, B., \& Risley, T. R. (1995). Meaningful differences in the everyday experiences of young American children. Baltimore: Brookes.

Heath, S. B. (1989). Oral and literate traditions among black Americans living in poverty. American Psychologist, 44, 367-373.

Hollingshead, A. B. (1975). Four factor index of social status. New Haven, CT: Yale University, Department of Sociology.

Juffer, F., Hoksbergen, R. A. C., Riksen-Walraven, J. M. A., \& Kohnstamm, G. A. (1997). Early intervention in adoptive families: Supporting maternal sensitive responsiveness, infant-mother attachment, and infant competence. Journal of Child Psychology and Psychiatry, 38, 1039-1050.

Kuhl, P. K., Andruski, J. E., Chistovich, I. A., Chistovich, L. A., Kozhevnikova, E. V., Ryskina, V. L., et al. (1997, August). Cross-language analysis of phonetic units in language addressed to infants. Science, 277, 684-686.

Landry, S. H., \& Chapieski, M. L. (1988). Visual attention during toy play exploration in preterm infants: Effects of medical risk and maternal interactions. Infant Behavior and Development, 11, 187-204.

Landry, S. H., Garner, P. W., Swank, P. R., \& Baldwin, C. D. (1996). Effects of maternal scaffolding during joint toy play with preterm and full-term infants. Merrill-Palmer Quarterly, 42, 177-199.

Landry, S. H., Miller-Loncar, C. L., Smith, K. E., \& Swank, P. R. (2002). The role of early parenting in children's development of executive processes. Developmental Neuropsychology, 21, 15-41.

Landry, S. H., Smith, K. E., Miller-Loncar, C. L., \& Swank, P. R. (1998). The relation of change in maternal interactive styles to the developing social competence of full-term and preterm children. Child Development, 69, 105-123.

Landry, S. H., Smith, K. E., Swank, P. R., Assel, M. A., \& Vellet, S. (2001). Does early responsive parenting have a special importance for children's development or is consistency across early childhood necessary? Developmental Psychology, 37, 387-403.

Landry, S. H., Smith, K. E., Swank, P. R., \& Miller-Loncar, C. L. (2000). Early maternal and child influences on children's later independent cognitive and social functioning. Child Development, 71, 358-375.

Londerville, S., \& Main, M. (1981). Security of attachment, compliance, and maternal training methods in the second year of life. Developmental Psychology, 17, 289-299.

Maccoby, E. E., \& Martin, J. A. (1983). Socialization in the context of the family: Parent-child interactions. In P. H. Mussen (Series Ed.) \& E. M. Hetherington (Vol. Ed.), Handbook of child psychology: Vol. 4. Socialization, personality, and social development (4th ed., pp. 1-101). New York: Wiley.

MacDonald, K. (1992). Warmth as a developmental construct: An evolutionary analysis. Child Development, 63, 753-773.

Martin, J. (1989). Personal and interpersonal components of responsiveness. In M. H. Bornstein (Ed.), Maternal responsiveness: Characteristics and consequences (pp. 5-14). San Francisco: Jossey-Bass.

Mitchell, S. K. (1979). Interobserver agreement, reliability, and generalizability data collected in observational studies. Psychological Bulletin, 86, 376-390.

Olson, S. L., Bates, J. E., \& Bayles, K. (1984). Mother-infant interaction and the development of individual differences in children's cognitive competence. Developmental Psychology, 20, 166-179.

Parpal, M., \& Maccoby, E. E. (1985). Maternal responsiveness and subsequent child compliance. Child Development, 56, 1326-1334.

Patteson, D. M., \& Barnard, K. E. (1990). Parenting of low birth weight 
infants: A review of issues and interventions. Infant Mental Health Journal, 11, 37-56.

Preacher, K. J., \& MacCallum, R. C. (2003). Repairing Tom Swift's electric factor analysis machine. Understanding Statistics, 2, 13-32.

Raudenbush, S., \& Liu, X. (2001). Effects of study duration, frequency of observation, and sample size on power in studies of group differences in polynomial change. Psychological Methods, 6, 387-401.

Rogoff, B. (1990). Apprenticeship in thinking. New York: Oxford University Press.

Sameroff, A. J., Seifer, R., \& Zax, M. (1982). Early development of children at risk for emotional disorders. Monograph of the Society of Research and Child Development, 47(Serial No. 7), 1-82.

SAS Institute. (1999). SAS OnlineDoc (Version 8) [Computer software]. Cary, NC: Author.

Sroufe, L. A. (1983). Infant-caregiver attachment and patterns of adaptation in preschool: The roots of maladaptation and competence. In M. Perlmutter (Ed.), Minnesota Symposium on Child Psychology (Vol. 16, pp. 41-81). Hillsdale, NJ: Erlbaum.

Tamis-LeMonda, C. S., Bornstein, M. H., \& Baumwell, L. (2001). Maternal responsiveness and children's achievement of language milestones. Child Development, 72, 748-767.

Tomasello, M., \& Farrar, M. J. (1986). Joint attention and early language. Child Development, 57, 1454-1463.
Trevarthen, C. (1988). Universal co-operative motives: How infants begin to know the language and culture of their parents. In G. Jahoda \& I. M. Lewis (Eds.), Acquiring culture: Cross cultural studies in child development (pp. 37-90). London: Croom Helm.

Van Egeren, L., Barratt, M. S., \& Roach, M. A. (2001). Mother-infant responsiveness: Timing, mutual regulation, and interactional context. Developmental Psychology, 37, 684-697.

Vygotsky, L. S. (1978). Mind in society. Cambridge, MA: Harvard University Press.

Wakschlag, L. S., \& Hans, S. L. (1999). Relation of maternal responsiveness during infancy to the development of behavior problems in highrisk youths. Developmental Psychology, 5, 569-579.

Weizman, Z. O., \& Snow, C. E. (2001). Lexical input as related to children's vocabulary acquisition: Effects of sophisticated exposure and support for meaning. Developmental Psychology, 37, 265-279.

Wertsch, J. V. (1979). From social interaction to higher psychological processes: A clarification and application of Vygotsky theory. Human Development, 22, 1-22.

Received August 13, 2004 Revision received November 1, 2005

Accepted November 29, 2005

\section{E-Mail Notification of Your Latest Issue Online!}

Would you like to know when the next issue of your favorite APA journal will be available online? This service is now available to you. Sign up at http://watson.apa.org/ notify/ and you will be notified by e-mail when issues of interest to you become available! 